\title{
A dyadic segmentation approach to business partnerships
}

\author{
Jacoues-Marie Aurifeille ${ }^{1}$ and Christopher John Medlin ${ }^{2}$
}

\begin{abstract}
In business science, the studied objects are often groups of partners rather than independent firms. Extending classical segmentation to these polyads raises conceptual problems, principally: defining what should be considered as common or specific at the partners' and at the segment levels. The general approaches consist either in merging partners characteristics and performances into a single macro-object, thus loosing their specific contributions to each partner's performance, or in modelling partners' performance as if their models were independent. As a step to understanding, how partnership influences firms' performance, the dyadic (i.e. two partners') case is studied. First, some theoretical issues concerning the degrees of individual and contributive interest in a dyadic population are discussed. Next, partnership's conceptualisation is based upon two models for each firm: a "self-model" that reflects how the firm's characteristics explain its own performance, and a "contributive-model" model that reflects how these characteristics influence the partner's performance. This allows definition of three relationship modes: merging, teaming and sharing. Subsequently, dyad segmentation strategies are discussed according to their capacity to reflect the modes of partnership and a dyadic clusterwise regression method, based on a genetic algorithm, is presented. Finally, the method is illustrated empirically using actual data of business partners in the software market.
\end{abstract}

Classification Codes: M1.

\section{Introduction}

It has been argued that actor bonds, the social attributes that exist in the space between alliance partners (Håkansson and Snehota, 1995), play a pre-eminent role in balancing self and collective interest (Medlin and Quester, 1999). However, it is natural that two firms in a dyad should have different views of that relationship (Anderson, Håkansson and Johanson, 1994). Thus, different types of relationships are bound to exist; depending

\footnotetext{
${ }^{1}$ University of La Réunion, FACIREM lab. E-mail: aurifeil@univ-reunion.fr

${ }^{2}$ School of Commerce, Adelaide University, 5005 Australia.

Keywords: Business partnership, relationships, segmentation, dyads, genetic algorithm.
} 
on the way motives for joint action are similar, or different, and on the preferred manner of operating social and economic environments within a relationship.

Yet, quantitative research on dyads has relied upon survey responses from one party reporting on the relationship ( $c f$. Anderson and Narus, 1990; Aulakh-Preet et SahayArvind, 1997; Heide and John, 1992; Morgan and Hunt, 1994; Nielson, 1998). This is partly a result of the difficulty of obtaining dyad data ( $c f$. Heide et al., 1992; Kim, 2000), but also a result of inadequate means of analysis. Where dyadic data has been collected, analysis has followed a "bonded" approach that aggregates partners into a single object, or on the independent modelling of each partner's behaviour (Gundlach, Achrol and Mentzer, 1995; Kim, 2000).

This paper provides a new approach to analysis of business dyads based upon segmentation techniques. A clusterwise prediction is proposed that retains each partner's way of achieving performance through self and collective models model. The first section outlines the variables involved in predicting performance in partnership. The next section outlines dyadic operation based upon two models for each firm: an "individual" and a "contributive" model. This conceptualisation of dyads allows discussion of a number of alternate dyad segments. In the third section, algorithms for facing these alternatives are presented. The fourth section presents an empirical illustration of dyadic segmentation based on actual dyad data. Finally, areas for future research are discussed.

\section{The variables involved in partners' economic performance}

Firms enter into relationships with suppliers, customers and significant partner organizations based on strategic plans (Axelsson and Easton, 1992; Borys and Jemison, 1989; Ford, 1990). These strategic plans represent a relationship "time perspective", founded on the belief that long-term coordinated action with another firm is important. At the heart of this strategy is an interest in maintaining future exchange based on expected net gains (Dwyer et al., 1987). A firm's "past experience" with acting collectively will also provide knowledge and skills that will shape the coordination process between the firms (Wilson, 1995).

This mutual alignment of firms' motivation involves the recognition of the role played by both self-interest and collective interest. The role of self-interest, in the form of "economic goals", is evident in the need for individual rewards as a basis for motivation to interact; while collective interest is partially displayed by the way the other party mediates the collective rewards through "commitment" and "trust".

Both self-interest and collective interest coexist in partnerships ( $c f$. Young and Wilkinson, 1997), however, in the final analysis, it will usually be economic results that provide indicators of "partnership performance" and these results matter at each firm's level. To model performance in a way that considers the partnership and the firm levels, a structural model (Jöreskog and Sörbom, 1996) was recently proposed (Medlin, 2001; Medlin, Aurifeille et Quester, 2001). It predicts dyadic performance by considering independently how partners are involved in the partnership. The significant variables emerged from the broader list of traits currently proposed in the partnership literature (Morgan, 1994; Anderson et al., 1994; Håkansson, 1995). This model predicts dyadic 


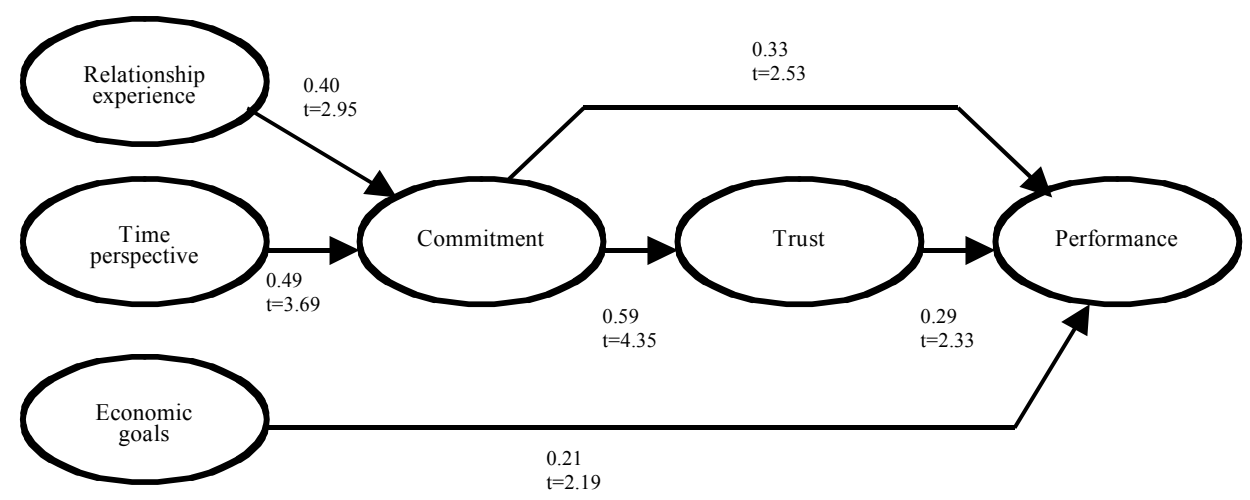

Fig. 1. Global Structural Model of Partners' Performance (Medlin, forthcoming 2000).

performance for 83 relationships in the business software industry (see Fig. 1). Appendices 1 and 2 provide the source of constructs and the structural model results.

Although the global model has an acceptable fit (squared correlation coefficient: $\mathrm{R}^{2}=0.40$, root mean square error of approximation: $R M S E A=0.049$ ), it provides an incomplete understanding of dyad performance because it considers performance at the global level and does not consider partner's interaction. Hence, a more precise analysis should be undertaken to uncover the models underlying a dyad's performance. The next section elaborates a dyadic performance model based on segmentation, conducted using the significant variables of Medlin's model (see App. 1 and 2).

\section{Dyad models: modes of operation}

We shall be using Aurifeille's approach to the marketing segmentation of couples of consumers (Aurifeille, 2001). The approach considers two models for each partner, meaning that four models are considered within a dyad. The first is a "self-model" that predicts a firm's performance from its individual characteristics, while not accounting for partner characteristics. The second is a "contributive" model that relates the firm's characteristics to the partner's performance. The same duality applies to the partner, so that any firm $i$ has a "self" model $S i$ and a "contributive" model $C i$. Thus, a dyad of two firms $i$ and $j$ is characterised by 4 models: $\mathrm{Si}, \mathrm{Sj}, \mathrm{Ci}$ and $\mathrm{Cj}$. This approach follows the IMP framework with the recognition that each firm's view of the relationship may be different (Anderson et al., 1994).

Three main dyadic situations may then be described by considering the $S$ and $C$ models (see Tab. 1).

The "merging" mode corresponds to firms with similar models at both the "self" and the "contributive" levels. Such dyads are not worried about a future merging and may even be explicitly so engaged. Firms in the "merging" mode would implicitly agree on complementary operating modes at the "contributive" level that not only complement their "self" model, but also contribute to the partner's performance. One may assume 
TABLE 1. Three main modes of relationship between two partners.

\begin{tabular}{c|c|c}
\hline \multirow{2}{*}{ Contributive model $(C)$} & \multicolumn{2}{|c}{ Self model $(S)$} \\
& Identical & Different \\
\hline Identical & Merging & Sharing \\
\hline Different & Teaming & N/A \\
\hline
\end{tabular}

that the lower the differences between the "contributive" and the "self" models, the greater the level of merging between the two firms. The extreme case of an identity of the four models would translate to a complete merging of the firms. Of course, some differences may exist between the "self" and the "contributive" models of firms in the "merging" mode, but they would be considered as fit errors to be reduced or even suppressed later.

The "teaming" mode corresponds to firms that follow the same "self" model and have different "contributive" models. In this mode the coordination between partners is more complex as each partner contributes differently from the other, analogous to a sport team where different roles are assigned to each player. For instance, one partner may rely on trust while the other would rely on previous partnership experience. Asymmetry between teaming firms could be observed, with one firm managing different "contributive" and "individual" models, while its partner would follow a same model for its "self" and "contributive" operation ( $c f$. Wilson, 1995). This might translate differences in flexibility, the firm able to manage different models being more flexible than its partner. Conversely, this might translate dominance of one firm over the other, with the weaker one being forced to accept some discrepancy between its self and its contributive models.

The "sharing" mode corresponds to firms that follow different "individual" models, whatever their "contributive" models. Partners have different ways to achieve individual performance, indicating that dyadic performance is a constraint rather than a goal.

Following Aurifeille (2001), five main modes of partnership may be identified. These five modes may be represented graphically (see Fig. 2).

Though this formalisation has some shortcomings it has three major advantages. It provides:

- a simple overview of partnership modes;

- information on asymmetric relationships;

- a dynamic perspective, as suggested by the different stages of merging.

The mode of partnership, that is to say the similarities between the $C i, C j, S i$ and $S j$ models can be identified by making a clusterwise regression analysis of all the $C$ and $S$ models that predicts firms performances. In the complete merging case, the four models of a dyad will be grouped in the same cluster, meaning that they all refer to the cluster's model. In the teaming case, a dyad's $S$ models will belong to the same predictive cluster, and its $C$ models will belong to different other clusters.

The next section presents an empirical test of the above formalisation, based on: - the existence of predictive clusters (i.e. clusterwise models with significant parameters and acceptable fit) as measured by the sum of the squared prediction errors (SSE); 


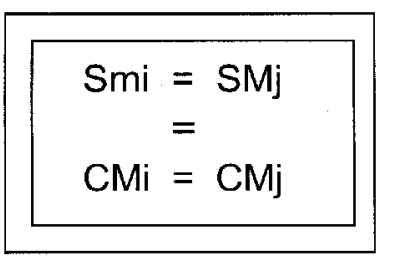

Complete merging

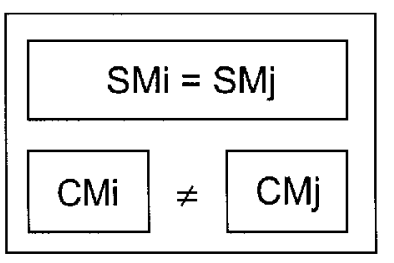

Teaming

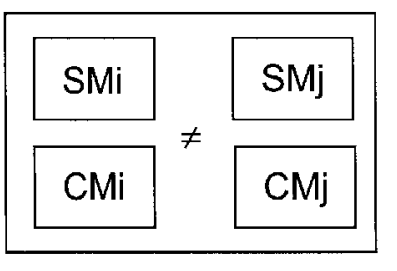

Sharing

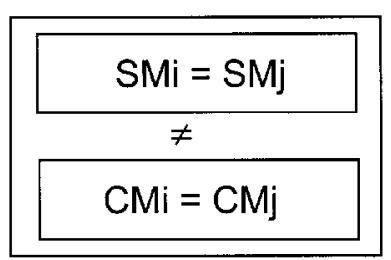

Pre-merging

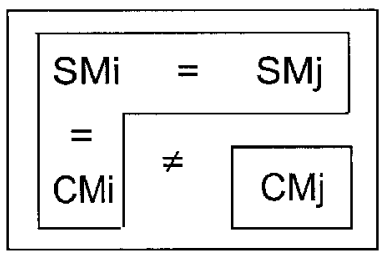

Asymetric teaming

Fig. 2. The five modes of partnership.

- the existence of external manifest variables (Number of employees, Firm Age, Single/ subsidiary firm, Number of entered countries, Principal/agent) that can discriminate the generated clusters. As a complement to the model based clustering, these variables allow identification of the firms.

\section{Quantitative Dyadic Segmentation}

Schematically, clusterwise regression is a predictive clustering method, also called "segmentation". Clusters are determined according to the prediction of one or several dependent variables, rather than being purely descriptive as are the well-known k-means or hierarchical clustering algorithms. Clusterwise regression avoids the indeterminacy of the descriptive segmentation methods because it acknowledges the dependent variables that motivate the search for segments. In particular, it avoids the issues of deciding a relevant weighting or hierarchy among the independent variables.

Segmentation conforms with a Business Science orientation: namely to achieve specific segments based on economic goals, rather than looking for unlikely ontological 
types that would transcend any sampling of the independent variables. Typically, clusters of firms will be sought so that, in each one, the cash-flow generated by a firm can be correctly predicted by the same combination of traits (e.g. size, age, advertising, $\mathrm{R} \& \mathrm{D}, \ldots)$. In this paper, the dependent variable is the firm's performance and the independent variables are those identified in Medlin's model (Medlin, 2001). As a first test and following the usual approach of clusterwise regression, the goal function is:

$$
\min \left[\sum_{k=1}^{K} \sum_{i=1}^{I}\left(a_{i k}\left(y_{i}-\sum_{j=1}^{J} x_{i j} b_{j k}+c_{k}\right)^{2}\right)\right]
$$

with:

- $I$ firms, $K$ clusters, $J$ independent variables, one dependent variable $y$,

- parameters to be estimated: regression coefficients $\left(b_{j, k}\right)$ and constants $\left(c_{k}\right)$,

$-a_{i k}$ a binary variable indicating wether firm $i$ belongs to cluster $k$.

Among the numerous existing clusterwise regression heuristics, we have chosen to use a genetic algorithm (Goldberg, 1991; Holland, 1992). Justifying this choice in detail would exceed the size allowed for this paper. The interested reader may find discussions and empirical tests among non-connectionist algorithms in Wedel and Kamakura (1997) and with connectionist methods (simulated annealing, genetic algorithm) in Aurifeille (2000a) and in Aurifeille and Pinto (2000). Briefly, GA clusterwise regression heuristics are complex problems that benefit from a large number of explorers (the chromosomes) that comb stochastically the solution space and exchange information. Thus, GA generally exhibits more robustness and lower error scores than the clusterwise regression algorithms that rely on a single "explorer". Moreover, in comparison to the mixture regression model implemented in more formal heuristics (e.g. regression mixture models; Wedel and DeSarbo, 1995; Wedel and Kamakura, 1997), the GA approach provides partitions instead of fuzzy clusters, thus providing clearer interpretation, a crucial condition in our dual-model approach of dyadic segmentation.

The GA algorithm that we use is standard (e.g. Goldberg, 1991):

i. Initiation: Assuming $J$ independent variables, fix a number of chromosomes, $c$, a number of clusters, $K$. Assign $(J+1) K b$ random values to each chromosome. These are the initial coefficients and intercept parameters of the $k$ models to be estimated, coded in $b$ bits. Fix a replacement rate, $r$, and a mutation rate, $m$. Usually $r$ is around $60 \%$ and $m$ is $1 \%$ of the total number of bits in the chromosome population.

\section{ii. Assignment:}

For each chromosome:

- assign each firm to the cluster whose parameters fit best the firm's performance;

- rank the chromosomes according to the sum of the squared prediction errors (SSE);

- if the $10 \%$ of chromosomes with the lowest have not changed across the latest $T$ iterations, go to vi. Otherwise, go to iii. Note that the value of $T$ depends on $J, K, c$ and $b$; it should be fixed empirically. 
iii. Estimation:

- Repeat $r c / 2$ times the following routine:

- draw two chromosomes using a biased random procedure so that the probability that a chromosome is chosen is inversely proportional to its $S S E$;

- draw a cutting point at random within the $[1,(J+1) c b]$ interval;

- cross the two chromosomes, by swapping the segments located after the cutting point. This generates two new chromosomes.

iv. Mutation:

- Repeat $m c$ times the following procedure:

- Choose a bit at random among the chromosome population and change its value, $v$, into $1-v$.

v. Replacement:

- Choose at random $r c / 2$ old chromosomes and replace them by the new ones.

vi. End of the algorithm.

\section{Quantitative results}

Among the 83 polyadic relationships analysed in Medlin's model described in Section 1, a total 34 dyadic partnerships. Since each partner of a dyad is characterized by two models, the number of objects to cluster is $2 \times 2 \times 34=136$.

Two analyses are presented: the clusterwise regression to understand the models underlying the partnership modes and an external analysis to score the three relationship modes.

Solutions with size ranging from 2 to 5 clusters have been investigated, with 30 tests conducted in order to have confidence intervals for the results. Table 2 recapitulates the main statistics. As would be expected, the number of sharing dyads is correlated positively with the number of clusters and the number of asymmetric teaming cases decreases. This results from the greater precision in the separation of the clusters.

As the sample used in the segmentation is doubled, the corresponding SSEs must be divided by two for comparison with the SSE of the global model ( $S S E=327)$. In all the segmented solutions, the SSE of the best solution is lower than the SSE of the global models. When the average $S S E$ of the segmented solutions is considered the difference is still significantly in favour of the segmented solution, except for the two-cluster solution. These results justify the use of a clusterwise regression methodology: segmentation significantly improves the fit of the dyadic performance model.

The results of the clusterwise regression analysis are interesting, for the "sharing" mode appears to be in majority for almost all solutions (see Tab. 2). Conversely, the "teaming" mode is only weakly represented, particularly if the "potential merging" mode is not counted. These results suggest partnerships in the studied sample rely importantly on "individual" level models.

A scree plot of the SSE versus the size of the solution (Fig. 3) shows an inflexion point between the 2 and the 3 cluster solutions, suggesting that beyond 3 classes most of the error reduction concerns random effects. Therefore, the external analysis will be 
TABLE 2. Mean and standard deviations of the frequencies of the dyads across the five partnership modes (standard deviation is between parentheses)

\begin{tabular}{|c|c|c|c|c|}
\hline \multirow{2}{*}{$\begin{array}{l}\text { Mode of } \\
\text { partnership }\end{array}$} & \multicolumn{4}{|c|}{ Size of the solution } \\
\hline & 2 & 3 & 4 & 5 \\
\hline$M E R G I N G$ & $\begin{array}{c}6 \\
(0)\end{array}$ & $\begin{array}{l}3 \\
(2)\end{array}$ & $\begin{array}{c}2 \\
(1.4)\end{array}$ & $\begin{array}{l}1.2 \\
(0.4)\end{array}$ \\
\hline PRE-MERGING & $\begin{array}{l}3.5 \\
(0.7)\end{array}$ & $\begin{array}{c}2 \\
(1.7)\end{array}$ & $\begin{array}{c}1 \\
(1.4)\end{array}$ & $\begin{array}{c}0.8 \\
(0.4)\end{array}$ \\
\hline SHARING & $\begin{array}{c}13 \\
(1.4)\end{array}$ & $\begin{array}{l}20.3 \\
(2.5)\end{array}$ & $\begin{array}{c}23 \\
(1.2)\end{array}$ & $\begin{array}{c}24 \\
(2.8)\end{array}$ \\
\hline TEAMING & $\begin{array}{c}15 \\
(1.4)\end{array}$ & $\begin{array}{l}10.7 \\
(2.1)\end{array}$ & $\begin{array}{c}9 \\
(1.4)\end{array}$ & $\begin{array}{l}8.8 \\
(2.6)\end{array}$ \\
\hline $\begin{array}{l}\text { ASSYMETRY } \\
\text { TEAMING }\end{array}$ & $\begin{array}{c}15 \\
(1.4)\end{array}$ & $\begin{array}{c}7.3 \\
(1.5)\end{array}$ & $\begin{array}{c}3.5 \\
(0.6)\end{array}$ & $\begin{array}{c}3.8 \\
(1.5)\end{array}$ \\
\hline $\begin{array}{l}\text { Best SSE } \\
\text { Mean } \\
\text { Std }\end{array}$ & $\begin{array}{l}655 \\
839 \\
(99)\end{array}$ & $\begin{array}{l}341 \\
441 \\
(51)\end{array}$ & $\begin{array}{l}250 \\
340 \\
(47)\end{array}$ & $\begin{array}{l}207 \\
274 \\
(47)\end{array}$ \\
\hline
\end{tabular}

completed on the best 3 cluster solution. Other measures of fit that adjust for complexity could also be used to identify the best solution, for example information-theoretic measures (AIC, CAIC, ECVI, Bozdogan, 1987). However, these rely on maximum likelihood estimators, which our clusterwise regression GA does not support.

The external analysis resulted in only one significant variable: the number of employees $(p=0.025)$. The average of each partnership mode is indicated in Table 3 . It appears that merging dyads correspond to smaller firms and in particular are associated with the "potential merger" mode of partnership.

The large firms appear to be engaged in teaming operations. While most teaming is asymmetric, the largest firms appear to prefer full teaming. This could mean that they have the capacity to manage different "contributive" models and so accommodate their

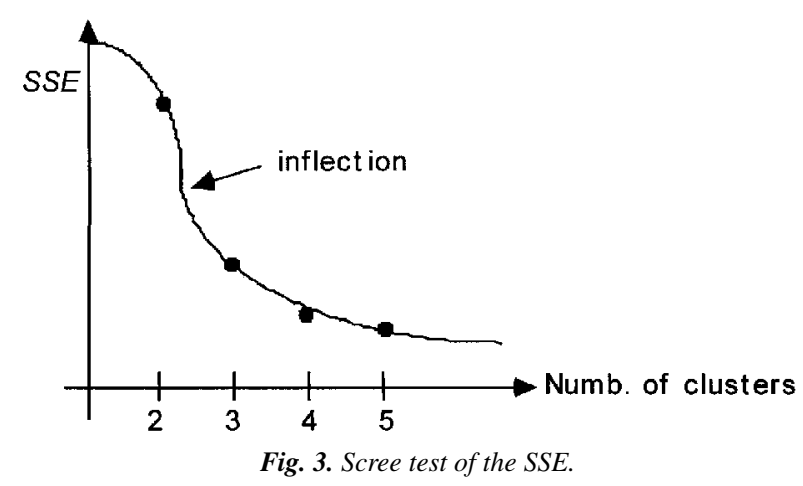


TABLE 3. Average number of employees across modes of partnership.

\begin{tabular}{|c|c|c|c|c|c|}
\hline Mode & Merging & Pre-merging & Sharing & Teaming & $\begin{array}{c}\text { Asymmetric } \\
\text { teaming }\end{array}$ \\
\hline Employees & 59.9 & 16.7 & 65.2 & 712.5 & 54.6 \\
\hline
\end{tabular}

smaller partners, while among the other firms the situation is less clear-cut. These results suggest only one possible route from teaming to complete merging (i.e. asymmetric $\rightarrow$ pre-merging $\rightarrow$ merging), as an evolution from asymmetric teaming to symmetric teaming would stabilise in the second stage. This is an interesting result, for the route to pre-merging, via asymmetric teaming requires one party to have a "contributive" model that corresponds to the joint "individual" models so that the differences between the parties is bridged. This result supports the role of the careful use of influence in the development of relationships ( $c f$. Dwyer et al., 1987).

The models fitted in each cluster are indicated in Table 4. These are parsimonious models, comprising only the variables with a significant effect $(p<0.05)$. The complexity of the models varies significantly across the clusters. Cluster one has a simple, trustbased model, while cluster three has a complex four determinant model. In between, cluster two is based on only two variables. An analysis of the correspondence between clusters and partnership modes clarifies this phenomenon. However, we now comment on the main results of Table 4, before analysing these underlying effects of partnership modes in Table 5.

In all models, "trust" plays an important positive role, suggesting that it has a key function in explaining dyadic performance at the "individual" and "contributive" levels. This result presents further support for the role of trust in relationship development (Achrol, 1997; Aulakh-Preet et al., 1997; Morgan et al., 1994). Indeed, it is the only variable that determines performance in segment one.

Conversely, in all models, "commitment" has no significant effect. This may result from the fact that its variance is already accounted for by the "relationship experience" and the "time perspective" variables. This is an interesting result as past conceptualisation of relationships has relied upon a structure of "commitment inputs" to explain continuance (Gundlach et al., 1995). This result suggests that in dyadic research "commitment" may be redundant and that its role may be usurped by more fundamental variables. If this is the case, a more parsimonious vision of dyadic performance may be gained by removal of the "commitment" construct.

Moving now to an analysis of the correspondence between clusters and partnership modes. The small sample size meant that this analysis was completed using only the main partnership modes: merging, sharing and teaming without their sub-cases. Table 5 gives the resulting correspondence table. The chi-square test (probability $p=0.000$ ) indicates that there is a significant relationship between the cluster and the mode of partnership. However, this result must be treated with some caution due to the low frequencies in some cells.

Table 5 shows that cluster 1 , the one based mostly on trust, is exclusively related to sharing situations. This suggests that trust is particularly important when the partners 
TABLE 4. Models of dyadic performance at the cluster level.

\begin{tabular}{|c|c|c|c|c|c|}
\hline Cluster & Frequency & Adj. $R^{2}$ & Signif. var. & Std. coeff. & $P$ value \\
\hline 1 & 24 & 0.862 & Trust & 0.406 & 0.049 \\
\hline \multirow{2}{*}{2} & \multirow{2}{*}{56} & \multirow{2}{*}{0.653} & Trust & 0.500 & 0.000 \\
\cline { 4 - 6 } & \multirow{2}{*}{56} & & Time persp. & 0.450 & 0.000 \\
\hline \multirow{2}{*}{3} & \multirow{2}{*}{0.850} & Trust & 0.311 & 0.000 \\
\cline { 4 - 6 } & & & Time persp. & 0.257 & 0.000 \\
\cline { 4 - 6 } & & & Experience & 0.539 & 0.000 \\
\cline { 3 - 6 } & & & Eco. goal & 0.290 & 0.000 \\
\hline
\end{tabular}

follow independent models and have different economic goals. This result indicates the central role of trust in situations where control is not possible. Thus, trust effectively replaces control processes such as hierarchies. This function of trust is well commented upon in the literature (Bonoma, 1976; Bradach et al., 1989; Luhmann, 1979); what is important here is that the result is found in a dyadic study.

Teaming is represented in cluster 3 more than in the other solutions. This is consistent with the idea that teaming means complementarity, that is good coordination of the partners' roles, which also reflects the more complex model at work in cluster 3 . The role of time perspective and economic goals in explaining performance in cluster 3 reflects the need for relationships to have a long-term time perspective so that coordination maybe achieved to gain economic goals (Dwyer et al., 1987). Thus, the results for cluster 3 provide evidence of the need to balance self and contributive interest to achieve relationship performance, reflecting the tension between conflict and cooperation in distribution channels (El-Ansary et al., 1972; Skinner et al., 1992). Merging also requires some model complexity, as indicated by its presence only in clusters 2 and 3 .

TABLE 5. Cross-tabulation of clusters and partnership modes.

\begin{tabular}{|c|c|c|c|c|}
\hline Cluster & Merging & Sharing & Teaming & Total \\
\hline 1 & 0 & 4 & 0 & 4 \\
\hline 2 & 2 & 9 & 2 & 13 \\
\hline 3 & 2 & 11 & 4 & 17 \\
\hline Total & 4 & 24 & 6 & 34 \\
\hline
\end{tabular}

\section{Conclusion}

This paper pioneers dyadic analysis of business relationships, a research stream that, until now, has relied upon either qualitative studies or individual respondent observation 
of a complex organization form. Although the findings commented upon here are based on statistically significant results, a cross-validation study would be necessary. Larger samples and dyads from other industries could provide interesting tests of the paper's findings. Within these limits, the empirical analysis of partners' performance has given results whose face validity (coherence, pertinence) and predictivity support the proposed formalization of dyadic partnership. By considering two models for each partner, a "selfmodel" that explains how a firm achieves performance and a "contributive-model" that explains how this firm contributes to the partner's performance, this formalization provides five modes of dyadic performance: "merging" (either complete or potential), "teaming" (either balanced or asymmetric) and "sharing".

It was empirically observed that solutions with more than two clusters improved significantly the fit of a global Lisrel model and enabled a simplification of the models. The "trust" determinant is confirmed as an essential variable in all clusters, particularly when a "sharing" mode of partnership is adopted. Conversely, the "commitment" variable appears to be redundant at the dyad level, simply reflecting the two more basic determinant constructs of "time perspective" and "partnership experience". This is an interesting finding as it indicates that trust is the central construct in relationship formation, rather than commitment, as suggested by Morgan and Hunt (1994).

Firms engaged in a "teaming" partnership appear to follow a more complex model that includes almost all of the determinants of performance, in particular the economic goals. This complex model corresponds to the complementary roles of the "teaming" partners.

The external analysis of the embedded modes, pre-merging and asymmetric teaming, provides further understanding of the partnering phenomena. Larger firms tend to manage their "individual" and "contributive" models differently by revealing more flexibility and adaptability to their partners than smaller firms. Thus, if relationships begin with a "sharing" mode, the path to "merging" mode can only be via asymmetric to premerging to merging. Conversely, an evolution from asymmetric teaming to symmetric teaming would stabilise in the second stage. These dynamics of relationship evolution deserve further research.

The proposed methodology opens several research tracks. By analysing teaming asymmetries, some light might be shed on the flexibility of the partners and on the variables that determine it? The existence of specific paths leading from one mode of partnership to another could also be identified and would deserve further research. At the quantitative level, the main research issue would be to extend this dyadic procedure to polyadic partnerships, for instance by conceptualising cases of triangular partnerships. 


\section{Appendix 1}

TABLE A1. Constructs, Sources and Scales.

\begin{tabular}{|l|c|l|}
\hline Construct & $\begin{array}{c}\text { Number } \\
\text { of items }\end{array}$ & Source \\
\hline Relationship experience & 2 & Developed for present study* \\
\hline Time perspective & 2 & Adapted (Anderson et al., 1994) \\
\hline Economic goal & 2 & Developed for present study* \\
\hline Commitment & 2 & Adapted (Aulakh-Preet et al., 1997; Holm et al., 1997) \\
\hline Trust & 3 & Adapted (Morgan and Hunt 1994) \\
\hline Performance & 2 & Adapted (Aulakh-Preet et al., 1997)* \\
\hline
\end{tabular}

* Measurement Scales developed for this study.

Economic Goal: For each goal indicate its relative importance to your firm's overall strategy with regard to the focus relationship. Market Share, Market Share Growth (1: extremely important - 9: not important).

All items were measured on a 9 point scale: strongly agree to strongly disagree.

Relationship: 1. In our firm's past relationships, the parties have treated problems as joint rather than individual responsibilities.

Experience: 2. Our firm prefers to work out solutions to problems that benefit the relationship as a whole, and not only the individual parties.

Relationship: Relative to your firm's expectations in the focus market what has been the performance of the inter-firm relation.

Performance: On the following dimensions: market share, market share growth (1: extremely strong - 9: not strong).

\section{Appendix 2}

TABLE A2. Structural Model Results.

\begin{tabular}{|l|c|c|c|c|}
\hline & Item & Lambda & $t$-value & $R^{2}$ \\
\hline Relationship experience & 1 & 0.90 & 6.94 & 0.81 \\
& 2 & 0.60 & 5.04 & 0.36 \\
\hline \multirow{2}{*}{ Time perspective } & 1 & 0.78 & 7.52 & 0.60 \\
& 2 & 0.87 & 8.54 & 0.76 \\
\hline \multirow{2}{*}{ Economic goal } & 1 & 0.96 & 9.49 & 0.81 \\
& 2 & 0.89 & 8.69 & 0.79 \\
\hline \multirow{2}{*}{ Commitment } & 1 & 0.93 & 7.64 & 0.86 \\
& 2 & 0.84 & 7.38 & 0.71 \\
\hline \multirow{2}{*}{ Trust } & 1 & 0.90 & 9.57 & 0.81 \\
& 2 & 0.91 & 9.66 & 0.83 \\
& 3 & 0.85 & 8.88 & 0.72 \\
\hline \multirow{2}{*}{ Performance } & 1 & 0.96 & 10.93 & 0.92 \\
& 2 & 0.97 & 10.91 & 0.94 \\
\hline
\end{tabular}

Note: Interfactor correlations are as follows:

Relationship experience and Time perspective: $\phi=0.39(t=3.21)$;

Relationship experience and Economic goal: $\phi=-0.08(t=-0.61)$;

Time perspective and Economic goal: $\phi=0.41(t=3.81)$. 


\section{References}

Achrol R.S. (1997) Changes in the theory of interorganizational relations in marketing: Toward a network paradigm, Journal of the Academy of Marketing Science 25, pp. 56-71.

Anderson J.C., Håkansson H., Johanson J. (1994) Dyadic business relationships within a business network context, Journal of Marketing 58, pp. 1-15.

Anderson J.C., Narus J.A. (1990) A Model of distributor firm and manufacturer firm working partnerships, Journal of Marketing 54, pp. 42-58.

Aulakh P.S., Kotabe M., Sahay A. (1997) Trust and performance in cross-border marketing partnerships: a behavioural approach, Journal of International Business Studies 27, pp. 10051032.

Aurifeille J.-M. (2000) A Bio-mimetic approach to marketing segmentation: Principles and comparative analysis, European Journal of Economics and Social Systems 14, pp. 93-108.

Aurifeille J.-M. (2001), Le processus de décision dans les couples de consommateurs, Ciencias empresariales, 12, pp. 26-35.

Aurifeille J.-M., Pinto M.-P. (2000) Methodological and empirical issues in market segmentation: A comparison of the formal and the bio-mimetic methods, Fuzzy Economic Review V, pp. 43-60.

Axelsson B., Easton G. (Eds.), (1992) Industrial Networks: A New View of Reality. Routledge, New York.

Bonoma T. (1976) Conflict, cooperation and trust in three power systems, Behavioral Science 21, pp. 499-514.

Borys B., Jemison D.B. (1989) Hybrid arrangements as strategic alliances: Theoretical issues in organisational combinations, The Academy of Management Review 14, pp. 234-49.

Bozdogan H. (1987) Model selection and Akaike's information criterion (AIC), Psychometrika 52, pp. 345-370.

Bradach J.L., Eccles R.G. (1989) Price, authority, and trust: From ideal types to plural forms, Annual Review of Sociology 15, pp. 97-118.

Cattell R.B. (1996) The Meaning and strategic use of factor analysis. In: Handbook of Multivariate Experimental Psychology, Cattell R.B. (Ed.), Rand McNally, Chicago.

Dwyer R.F., Schurr P.H., Oh S. (1987) Developing buyer-seller relationships, Journal of Marketing 51, pp. 11-27.

El-Ansary A.I., Stern L.W. (1972) Power measurement in the distribution channel, Journal of Marketing Research 9, pp. 47-52.

Ford D. (Ed.). (1990) Understanding Business Markets: Interaction, Relationships and Networks. Academic Press, London.

Goldberg D.E. (1991) Genetic Algorithms. New York, Addison-Wesley.

Gundlach G.T., Achrol R.S., Mentzer J.T. (1995) The Structure of commitment in exchange, Journal of Marketing 59, pp. 78-92.

Håkansson H., Snehota I. (Eds.), (1995) Developing Relationships in Business Networks. International Thomson Business Press, London.

Heide J.B., John G. (1992) Do norms matter in marketing relationships ?, Journal of Marketing 56, pp. 32-44.

Holland J.H. (1992) Adaptation in Natural and Artificial Systems. University of Michigan Press, MIT Press, (2nd ed.), Cambridge, MA. 
Holm D.B., Eriksson K., Johanson J. (1997) Business networks and cooperation in international business relationships, Journal of International Business 27, pp. 1033-1053.

Jöreskog K.G., Sörbom D. (1996) Lisrel VIII. SSI, Chicago.

Kim K. (2000) On Inter-firm power, channel climate, and solidarity in industrial distributorsupplier dyads, Journal of the Academy of Marketing Science 28, pp. 388-405.

Luhmann N. (1979) Trust and Power. John Wiley, New York.

Medlin C.J. (2001), Relational Norms and Relationship Classes: From Independent Actors to Dyadic Interdependence. $\mathrm{Ph}$. D. Thesis, Adelaide University. (Unpublished).

Medlin C.J., Aurifeille J.M., Quester P.G. (To appear) An Empirical test of a model of relational norms and relationship performance. In: Actes de la cinquième conférence de recherche sur le Relationship Marketing, November 2000, Emory University, Atlanta.

Medlin C.J., Quester P.G. (1999) Actor bonds and relational norms in networks. In: Proceedings of the 15th Annual IMP Conference, Dublin.

Morgan R.M., Hunt S.D. (1994) The Commitment-trust theory of relationship marketing, Journal of Marketing 58, pp. 20-38.

Nielson C.C. (1998) An Empirical examination of the role of closeness in industrial buyerseller relationships, European Journal of Marketing 32, pp. 441-464.

Skinner S.J., Gassenheimer J.B., Kelley S.W. (1992) Cooperation in supplier-dealer relations, Journal of Retailing 68, pp. 174-93.

Wedel M., De Sarbo W.S. (1995) A Mixture likelihood approach for generalized linear models, Journal of Classification 12, pp. 21-55.

Wedel M., Kamakura W.A. (1997) Market Segmentation: Conceptual and Methodological Foundations. Kluwer, Dordrecht.

Wilkes G.A., Krebs W.A. (Eds.), (1985), Collins Concise English Dictionary. Collins, Sydney.

Wilson D.T. (1995) An Integrated model of buyer-seller relationships, Journal of the Academy of Marketing Science 23, pp. 335-346.

Young L.C., Wilkinson I.F. (1997) The Space between: Towards a typology of interfirm relations, Journal of Business-to-Business Marketing 4, pp. 53-97.

To access this journal online: www.edpsciences.org 